\title{
Factors impacting library-related uses of mobile phones by students in public universities in Malawi
}

\author{
Aubrey Harvey Chaputula ${ }^{1}$ and Stephen Mutula ${ }^{2}$ \\ achaputula@yahoo.co.uk ORCID: orcid.org/0000-0003-3753-9934 \\ mutulas@ukzn.ac.za ORCID: orcid.org/0000-0003-3776-8104
}

\begin{abstract}
Received: 10 April 2018
Accepted: 21 July 2018
\end{abstract}

\begin{abstract}
The purpose of this paper is to report on findings of a study that was conducted to determine academic and library-related uses of mobile phones by students in public universities in Malawi. The study surveyed students at Mzuzu University, Lilongwe University of Agriculture and Natural Resources, Kamuzu College of Nursing, the Polytechnic, and the College of Medicine. Self-completion structured questionnaires were administered to a sample of 370 students. The data collected was analysed using Statistical Package for the Social Sciences (SPSS) and the results are presented in the form of percentages, tables and graphs. Findings indicated that mobile phone ownership among the students was very high with $99.7 \%$ of the respondents owning one or more mobile phones. Findings further showed that students used mobile phones for searching e-books, e-journals, the library website and the catalogue. Most of the students indicated that ease of accessing services using mobile phones (200; 88.1\%), and the internet's ability to be accessed from anywhere at any time (185; $81.5 \%)$ positively impacted on their use of mobile phones. Conversely, the high cost of mobile internet and websites not being mobile-friendly were the notable factors that negatively impacted the use of mobile phones. Studies of this nature have not been previously conducted in public universities in Malawi. This study will, therefore, inform researchers intending to conduct similar or related studies in public universities in Malawi.
\end{abstract}

Keywords: Mobile phones, ownership, uses, university students, public universities, Malawi

\section{Introduction}

Mobile phones (feature phones and smartphones) have of late become ubiquitous among university students (Brooks 2016, Haverila 2013). Ownership of feature phones has in some studies reached the 100\% mark (De Wee 2013, Dewah and Mutula 2013); that of smartphones is steadily edging towards reaching the same threshold (Brookes 2016, Nowlan 2013). If the trend continues, it is anticipated that smartphone ownership will reach saturation point within the next few years.

University libraries in various parts of the world are taking advantage of the proliferation of mobile phones among students (Brooks 2016, Kumar 2014) coupled with the tremendous computing power they possess (Hossain \& Ahmed 2016) to offer services to their clients (Bomhold 2014, Luo 2014). Mobile phones are used to deliver user services (book renewals; e-book and e-journal access), reference services (user queries and instructional services), informational services (notifications), and others. Mobile phones, particularly smartphones, are increasingly used to provide library and information services because they have the potential to enhance access to library resources beyond the normal opening hours and hence can assist to overcome the obstacles of time and space (Malik and Mahmood 2013), bringing more convenience to library users (Ballard and Blaine 2013). Moreover, mobile phones can help to provide access to eresources to students who do not have access to institutional computer facilities in resource-poor environments such as those in Africa (Palumbo 2014).

Studies have shown that university students have largely responded positively to the availability of library and information services on mobile phone platforms through increased usage (Kubat 2017, Hossain and Ahmed 2016). Much as this is the case, usage of the services ranks lower when compared to other services that students access using their mobile phones, including communicating with friends and family through calls, text, SMS, or email; connecting to social media tools such as Facebook; and playing games (Lo et al. 2016, Vassilakaki, Moniarou-Papaconstantinou \& Garoufallou 2016). Other studies have pointed to technological characteristics associated with mobile phones such as the

1. Aubrey Chaputula is Senior Assistant Librarian, Mzuzu University, Malawi

2. Stephen Mutula is Professor in the Information Studies Programme and Acting Deputy Vice-Chancellor: College of Humanities, University of KwaZulu-Natal, South Africa 
small screen size, slow internet speed and cost of accessing services as factors militating against access to library services offered through mobile phones (Luo 2014, De Wee 2013). Nevertheless, the small screen size of most mobile phones, slow internet speed and cost, among others, seem not to have affected university students' use of mobile phone for social or communication purposes (Lo et al. 2016, Vassilakaki, Moniarou-Papaconstantinou \& Garoufallou 2016). Thus, other challenges beyond what is stated in the literature exist that affect usage of mobile phones for accessing library services. This study was, therefore, undertaken to uncover such challenges, and it addressed the following research questions:

- What are the ownership rates of mobile phones by students in public universities in Malawi?

- What are the library-related uses of mobile phones by students in public universities in Malawi?

- Which factors impact usage of mobile phones by students?

Mobile phones have the potential to change library service delivery in the tertiary educational sector. Therefore, studies such as this one are vital as they would pave the way for policy, practical and managerial interventions in areas of infrastructure development, capacity building, awareness creation, institutional framework and budgetary support, among others, to enhance use of mobile phones to provide library and information services not only in public university libraries in Malawi but also beyond.

\section{Theoretical framework}

This study was underpinned by the Unified Theory of Acceptance and Use of Technology (UTAUT). UTAUT is a model that is often used in Information and Communications Technologies (ICT) related studies. The model was developed and validated by Venkatesh et al. (2003) through the review, mapping and integration of eight dominant theories and models that originated from different theoretical disciplines such as psychology, sociology and information systems (Williams, Rana \& Dwivedi 2012, Kijsanayotin, Pannarunothai \& Speedie 2009).

UTAUT was developed on the basis that constructs of existing theories were similar in nature, therefore, it was logical to map and integrate them to create a unified theoretical basis (Venkatesh et al. 2003). The model identifies four key drivers of the adoption of information systems: performance expectancy, effort expectancy, social influence and facilitating conditions (Martin and Herrero 2012). The model centres on two key issues, namely, behavioural intention and actual usage. Performance expectancy, effort expectancy and social influence impact behavioural intention which in turn influences actual usage. Empirical studies have shown that facilitating conditions, on the other hand, do not have any influence on behavioural intention but directly influence actual usage (Venkatesh et al. 2003). Besides the four main constructs of the model, UTAUT identifies the moderating effect of four other factors, those of gender, age, experience and voluntariness of usage (Keong et al. 2012), as illustrated in Figure 1.

Figure 1 UTAUT

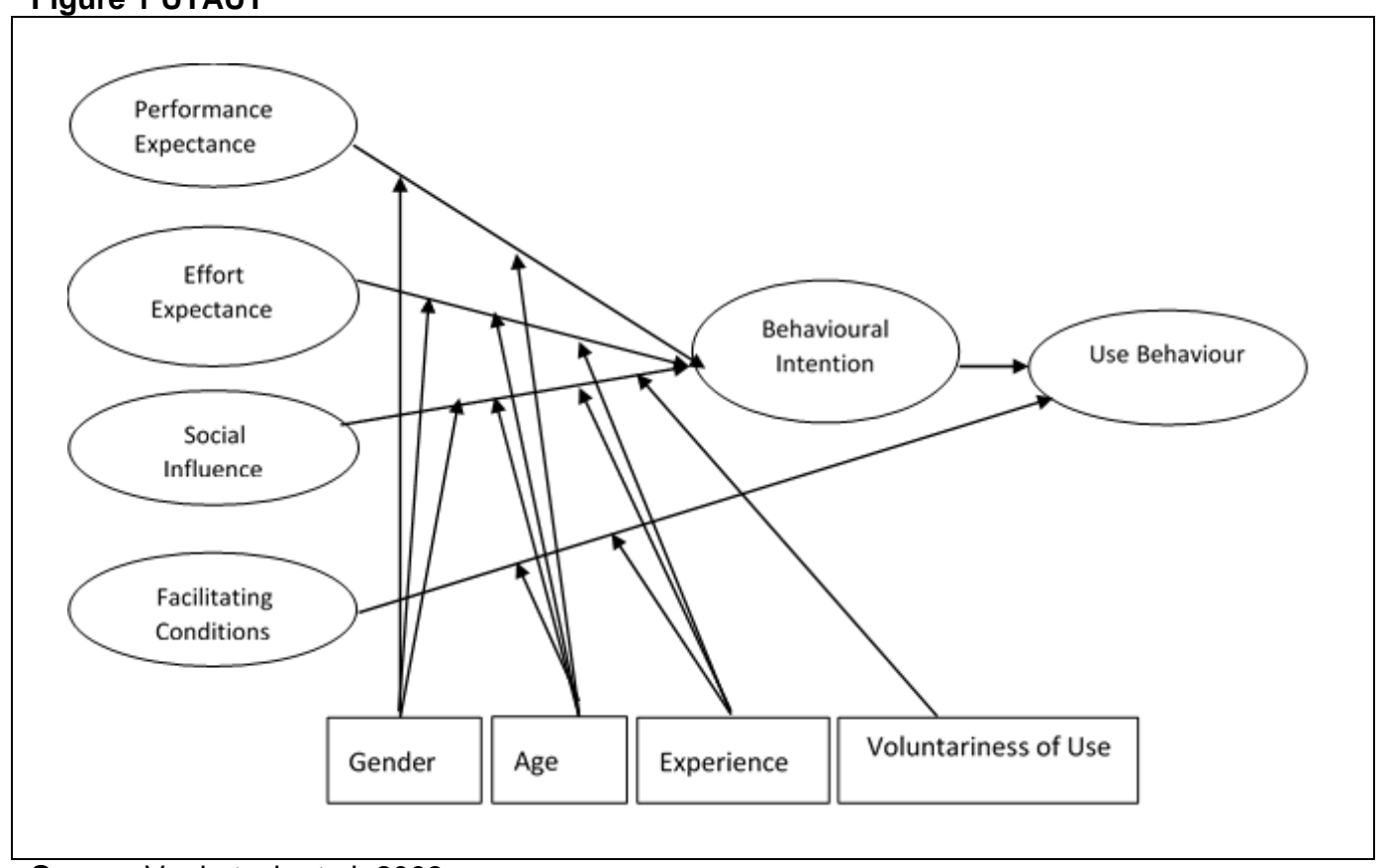

Source Venkatesh et al. 2003 
The strength of the UTAUT model lies in the fact that it was founded on so many models and thus provides the researcher with a broader view of all existing models. Moreover, UTAUT is a much stronger model as it accounts for an explanatory power of up to $70 \%$, unlike the other previous models that account for only between $17 \%$ and $53 \%$ of the variance in use intentions (Venkatesh et al. 2003). UTAUT has its own weaknesses too. Scholars such as Straub and Burton-Jones (2007) have claimed that the ten constructs of UTAUT are not parsimonious. Despite this weakness, use of UTAUT in this study is justified on the basis that its strengths far outweigh its weaknesses. Besides, the model has been used in other related studies such as the study of the adoption of mobile devices (Carlsson et al. 2006), the use of 'near field communication' (NFC) adoption of mobile phone service (Chen and Chang 2013), the use of mobile internet (Wang and Wang 2010) and library mobile applications in university libraries (Chang 2013).

\section{Literature review}

The literature that is reviewed below is grouped by theme, according to the research questions of the study.

\subsection{Mobile phone ownership}

Literature indicates that mobile phones (feature phones and smartphones) among university students the world over are ubiquitous (Brookes 2016, Zhang et al. 2016, Dahlstrom, Walker \& Dziuban 2013, Dahlstrom and Bichsel 2014, Kumar 2014). For instance, a study conducted by Becker, Bonadie-Joseph and Jonathan (2013) at Hunter College in New York that involved 613 students and made use of an open survey method, indicated that $98.7 \%$ of the students owned mobile phones. Similarly, the Educause Centre for Analysis and Research (ECAR) (2004) study found that only $1.1 \%$ of American undergraduate students owned a smartphone in 2004. However, recent ECAR studies (Brookes 2016, Dahlstrom, Walker \& Dziuban 2013, Dahlstrom and Bichsel 2014) show that smartphone ownership has grown exponentially over the past four years; shooting up from $76 \%$ in 2013 to $86 \%$ in 2014 before jumping further to $92 \%$ in 2015. Moreover, smartphone ownership increased from 92\% to $96 \%$ between 2015 and 2016.

A related study conducted by Kumar (2014) at Jawaharlal Nehru University (JNU) in India that involved a randomly selected sample of 180 students indicated that $93.89 \%$ of the students had either a smartphone or an ordinary phone. More importantly, this study revealed addictive tendencies associated with mobile phones among the students whereby many of the respondents $(71.6 \%)$ could keep a mobile phone close at all times while $82.25 \%$ stated that they could survive without food for one day but not without a mobile phone.

The researcher did not come across studies on student ownership of mobile phones in public universities in Malawi. Finding out ownership rates and functionality of those phones is key to determining their potential deployment in accessing library services. However, studies conducted on the African continent have similarly shown mobile phone ownership to be high among university students. A study conducted by Akeriwa, Penzhorn and Holmner (2015) at the University of Development Studies Library in Ghana that involved 155 graduate students found that $98.3 \%$ of the respondents owned a mobile phone. A study conducted by De Wee (2013) at the University of Pretoria revealed that all fifteen students interviewed owned an internet-capable mobile phone representing a $100 \%$ ownership rate. The study further revealed that two of the respondents owned two mobile phones, but the second mobile phone owned was not internet-capable. A more recent study conducted by Dewah and Mutula (2013) on mobile phone access and use among students at the National University of Science and Technology (NUST) in Zimbabwe, targeting fourth-year undergraduates and master's students found that all the students surveyed owned a mobile phone. A study conducted by Fasae and Adegbilero-Iwari (2015) that involved eighty science students in privately-owned Afe Babalola University and Joseph Ayo Babalola University in Nigeria revealed that $83.8 \%$ of the respondents used smartphones.

\subsection{Uses of mobile phones among students}

Literature shows that students deploy mobile phones in a variety of tasks but differ greatly in the way they use them. Vassilakaki, Moniarou-Papaconstantinou and Garoufallou (2016) conducted an online survey to investigate uses of mobile technology (laptop, desktop computer and mobile phone) among Library and Information Science undergraduate students in Greece. The study, which sampled 336 students and drew a response rate of $78.6 \%$, revealed that students' choice of which device to use depended on the task at hand. For instance, the respondents used their laptop, desktop computer and mobile phone to search for information $(63.6 \%, 49.4 \%$ and $20.8 \%$, respectively), to read an e-book ( $36.4 \%$, $26 \%$ and $23.4 \%)$ and e-journals $(35.1 \%, 31.2 \%)$, to send email $(62.3 \%, 42.9 \%$ and $29.9 \%)$, to search for information $(64.9 \%, 52 \%$ and $46.8 \%)$, and, finally, to download e-books (37.7\%, $27.3 \%$ and $18.2 \%)$. These findings indicate that the respondents preferred to use laptop and desktop computers over mobile phones for many academic and library-related activities. Similarly, laptop and desktop computers were preferred over the mobile phone in accessing the library's Online Public Access Catalogue (OPAC) (57.1\%, 36.4\% and 10.4\%), user's library account (58.4\%, 40.3\% and 26\%), searching for reference books (52\%, 37.7\% and 13\%), browsing new acquisitions list (39\%, 23.4\% and $20.8 \%)$ and reserving books 
(24.7\%, 20.8\% and 5.2\%). Conversely, the respondents used their mobile phones, laptops and desktop computers, in that order, to listen to music $(74 \%, 55.8 \%$ and $42.9 \%)$, to search for photographs $(77.9 \%, 63.6 \%$ and $45.5 \%)$, for chatting $(70.1 \%, 62.3 \%$ and $45.5 \%)$, to send a text message $(76.6 \%, 57.1 \%$ and $42.9 \%)$, for accessing social networking sites $(64.9 \%, 63.6 \%$ and $45.5 \%)$, to connect to the internet $(75.3 \%, 64.9 \%$ and $50.7 \%)$ and for playing online games $(61 \%$, $50.7 \%$ and $35.1 \%$ ). These findings imply that the mobile phone was mainly preferred for social activities than library or academic-related activities. Similarly, the ECAR (2015) study of United States of America (USA) undergraduate students' ownership and use of technology revealed that laptop computers were used more extensively for academic and libraryrelated purposes by the students when compared to smartphones (Brooks 2015). Findings indicated that 93\% of the students stated that laptops were very important for their academic success. On the contrary, only half of the respondents (46\%) stated that smartphones were extremely important for academic purposes.

Lo et al. (2016) conducted a study with the aim to explore art and design students' use of smartphones for accessing library services and learning at the Hong Kong Design Institute. The study, which surveyed fifty-one students, discovered that the majority of the respondents used their smartphones frequently (that is, at least once a week) for accessing reference materials and databases, as well as browsing the website and social networking sites for learning purposes. However, usage of smartphones for reading journal articles, e-books, as well as searching the library catalogue was minimal. These findings reflected those obtained in a study by Vassilakaki, Moniarou-Papaconstantinou and Garoufallou (2016) in Greece in that they show that, as much as respondents were prepared to use their smartphones for academic and library-related activities, such usage was much lower when compared to that of other technological devices such as laptops. Respondents in the study by Lo et al. (2016) indicated that the difficulty of browsing information on smartphones due to the design of the websites and applications made it problematic for them to utilise their smartphones for this purpose. Therefore, resolving these technological challenges is key in making the mobile phone a leading device for library-related activities.

In yet another study, Hossain and Ahmed (2016) used a questionnaire survey to investigate the use of smartphones for academic purposes by students at Dhaka University in Bangladesh. Findings of their study indicated that the majority of the students $(155 ; 74.9 \%)$ used their smartphones to read full-text articles. Other significant uses of smartphones were watching learning videos $(117 ; 56.5 \%)$, recording class notes $(94 ; 45.4 \%)$, and preparing class notes $(75 ; 36.2 \%)$. Much as the majority of the respondents used their smartphones for accessing full-text articles, which is a significant improvement from what was obtained in previous studies reviewed, use of smartphones for library reference $(48 ; 23.2 \%)$ was evidently low.

\subsection{Factors impacting usage of mobile phones to access library services by students}

Studies have shown that several factors exist that negatively impact access to library services offered through mobile phones by students. Availability and good performance of the wireless network infrastructure is one of them. On many university campuses, the Wi-Fi infrastructure either has limited coverage or is unreliable. For instance, the ECAR (2015) study of undergraduate students' ownership and use of mobile devices in the USA indicated that students living on campus rated their network experiences considerably lower than students living off-campus whereby only three in five students stated that they had reliable access to Wi-Fi throughout their campus (58\%) or in classrooms or instructional spaces (63\%) (Dahlstrom et al. 2015). The reason is due to the large number of mobile devices connected to the campus network. The USA study revealed that $61 \%$ of students connected at least two devices to the campus network at the same time. Although all institutions may face this challenge, it is particularly problematic in the developing world as inadequate funding for the procurement of bandwidth coupled with unreliable electricity supply all conspire to frustrate the provision of an efficient campus Wi-Fi network.

The literature has also shown that cost is a factor in accessing library and information services using a mobile phone. For instance, a study conducted by Song and Lee (2012) of international students enrolled at the College of Business at the University of Illinois found that the high total cost of ownership (costs for handsets and monthly data plans) was the main reason $39 \%$ of the respondents did not own a tablet computer. A study conducted by Luo (2014) at San Jose State University revealed that some of the respondents to the study did not access the SMS library service because they did not have a texting plan on their mobile phone contracts. Although cost has been identified as a factor in access to library services through mobile phones, trends of mobile phone usage as seen in studies by Lo et al. (2016) and Vassilakaki, Moniarou-Papaconstantinou and Garoufallou (2016) show that students still used their mobile phones to access social media and to communicate with their friends and relations using emails, SMS and chats. It is therefore possible that students are prepared to pay for services they value, and access to library services is not one of the services on which students consider it worth spending their financial resources. An alternative view could be the availability of alternative means of accessing library services, such as laptops or walking into the library to access the services, which have prompted some students to prioritise their spending on other services. 
In summary, the literature reviewed revealed that ownership of a mobile phone is key to accessing library services and resources through these devices. Much as this is the case, the type of mobile phone owned could have a bearing on use as mobile phones differ substantially in terms of power and functionality, which ultimately affects usage. Smartphones, for instance, are the most powerful type of mobile phone as they have computing power equivalent to that of some computers (Hossain and Ahmed 2016). Therefore, discovering mobile phone ownership rates and functionality is key to determining potential deployment of the mobile phones for accessing library services and resources. Technological characteristics of mobile phones and cost of accessing mobile phone services have also been highlighted as factors that could impact usage of mobile phones for accessing library services. However, the literature has shown that students use mobile phones more for communication and social networking than access to library services. The observed disparities in usage motivates questions of whether the technological factors and cost are indeed the main reasons for the reported low usage of mobile phones for accessing library services or whether other factors are responsible. This study intends to provide answers to this question.

\section{Methodology}

This study made use of a survey research design. Malawi has four public universities. They include the University of Malawi (UNIMA), Mzuzu University (MZUNI), Lilongwe University of Agriculture and Natural Resources (LUANAR) and the Malawi University of Science and Technology (MUST). UNIMA has four constituent colleges namely Chancellor College (CHANCO), Kamuzu College of Nursing (KCN), the Polytechnic and College of Medicine (COM) while the other universities only have one campus. Although potentially seven study institutions existed, this research covered only five of them: MZUNI, LUANAR, the Polytechnic, COM and KCN. Libraries selected for this study are affiliated to older and wellestablished institutions except MUST which was established in 2013 and did not have students in third, fourth and fifth years at the time of data collection. CHANCO was not included in the study despite being older and well established because permission was not secured to access the respondents. The combined student population in the institutions studied exceed 10,000.

Self-completion structured questionnaires were administered to a sample of 370 students in years three, four, five and postgraduates with a confidence level of $95 \%$ and a margin of error of $5 \%$. A decision to limit the study to students in levels three to five was made because they are involved in intensive research activities and hence capable of using their mobile phones for a wider range of purposes, including library use. In total, 316 students out of the 370 sampled responded to the questionnaire representing an $85.4 \%$ response rate. Reliability of some of the questionnaire items in this study were determined by calculating the Cronbach's Alpha values of the variables in the questions. The Cronbach's Alpha values were closer to 0.7 which shows that the items in the questionnaires used had high levels of internal consistency.

Research ethics was accomplished by, among others, getting gatekeepers' permission before entering the study sites, and soliciting the informed consent of the participants before administering the questionnaires. Data for this study was collected from November 2015 to March 2016 by the researcher with the aid of five research assistants. The data collected was analysed using Statistical Package for the Social Sciences (SPSS) Version 23 for descriptive statistics which have been presented in the form of tables and graphs.

\section{Findings and Discussion}

Findings are grouped below according to ownership of mobile phones, their internet capabilities, access to library resources and reference services, and factors impacting mobile phone usage in libraries.

\subsection{Mobile phone ownership}

Mobile phone ownership is one of the key determining factors for mobile phone use. It was for this reason that the researcher investigated general ownership of mobile phones among students. The study findings show that mobile phone ownership among students was very high with many of them owning one or more devices. Almost all students (315, 99.7\%) owned a mobile phone whilst only one indicated that he or she did not own a mobile phone. The high ownership rates of mobile phones observed in the current study resemble findings made in several other studies. A study carried out by Becker, Bonadie-Joseph and Jonathan (2013) at Hunter College in New York (USA) found that $98.7 \%$ of the students owned mobile phones. Studies by Dewah and Mutula (2013) in Zimbabwe, De Wee (2013) in South Africa and Fasae and Adegbilero-Iwari (2015) in Nigeria similarly recorded very high mobile phone ownership rates among students.

Three hundred and fourteen (314) out of the 315 students that indicated that they owned mobile phones responded to the question that sought to find out the number of mobile phones they owned (Figure 2). Findings revealed that, whereas $215(68.5 \%)$ students owned only one mobile phone, a significant part of the student body, ninety $(28.7 \%)$, owned two mobile phones. Seven (2.2\%) students owned three mobile phones and two (0.6\%) students owned more than 
three mobile phones. These findings imply that, as much as single ownership of a mobile phone was prevalent, dual and multiple ownership was increasingly becoming a trend which reflects what was found in studies conducted by De Wee (2013) in South Africa where students reported owning more than one mobile phone.

Figure 2 Mobile phone ownership among students $(\mathrm{N}=314)$

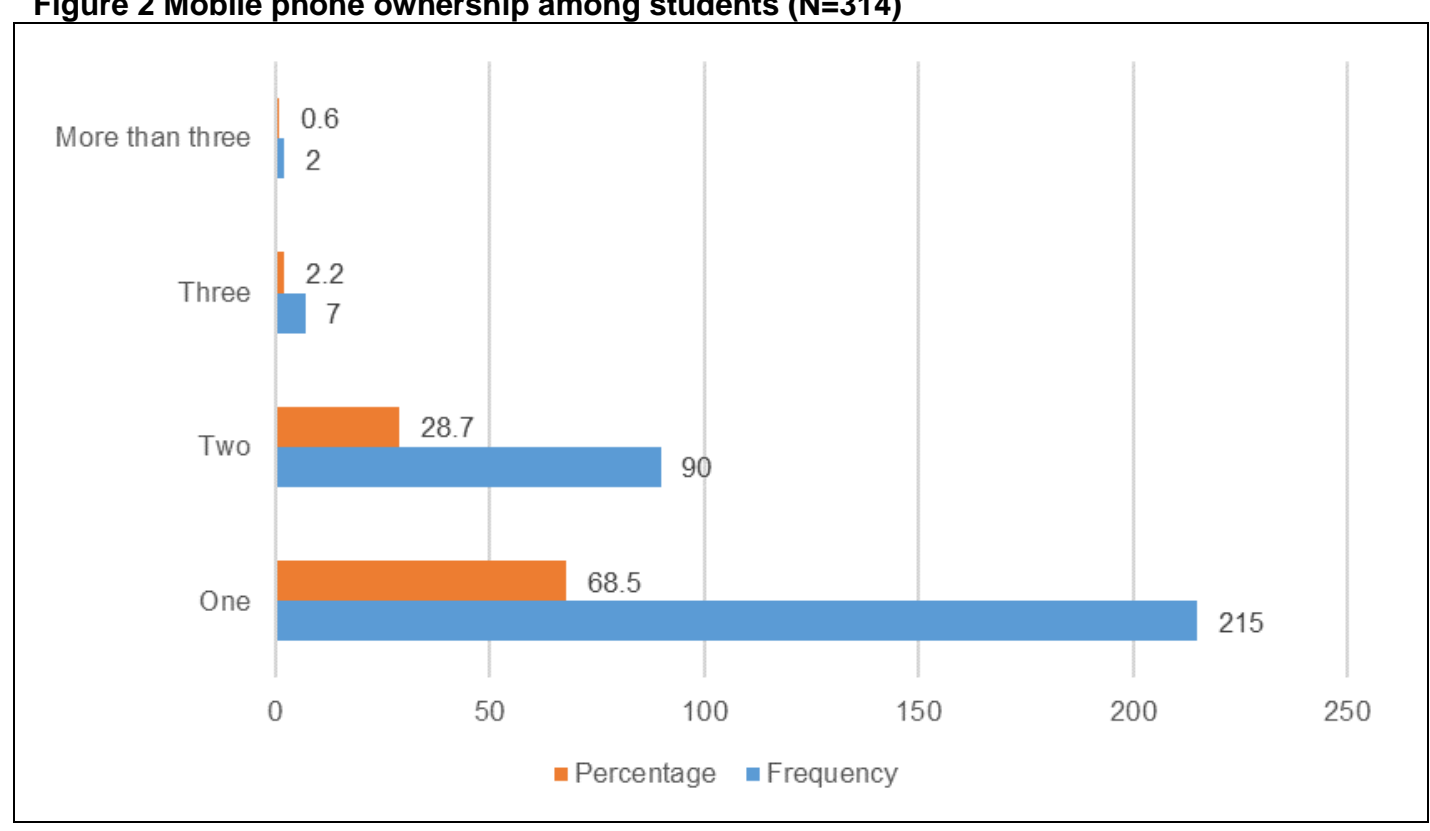

\subsection{Internet capability of the mobile phones owned by students}

As already indicated, the scope of the activities one can perform using a mobile phone is determined by the capabilities of the device owned. Internet-capable mobile phones, commonly referred to as smartphones, have bigger screens and possess more computing power than older mobile phones (Hossain and Ahmed 2016), a development that enables them to perform more functions. Considering that most library services are now web-based, the study probed internet capabilities of the mobile phones owned by students to get a picture of the students' capacity to access web-based library services using the mobile web.

Figure 3 Number of internet-capable mobile phones for respondents who owned more than one mobile phone (N=99)

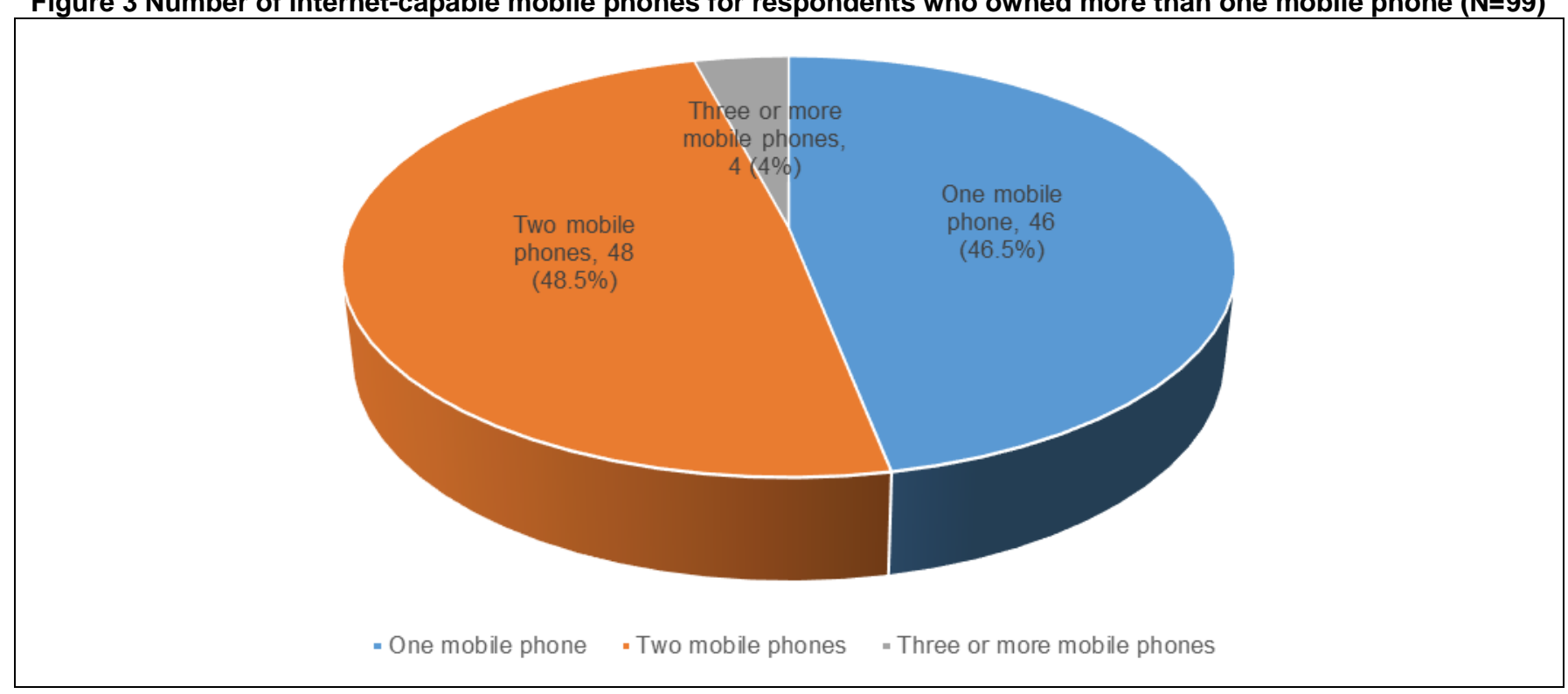

The study findings revealed that 299 (94.9\%) students owned mobile phones with internet capabilities while sixteen $(5.1 \%)$ owned mobile phones without this capability. Students who owned more than one mobile phone (ninety-nine) were asked to indicate how many of them had internet capabilities. Forty-eight $(48.5 \%)$ students stated that two of their mobile phones had this capability while forty-six (46.5\%) indicated that only one of their phones had internet capabilities. 
Moreover, four (4\%) students had three or more mobile phones that had internet capabilities. These findings are shown in Figure 3.

The findings presented in this section show that most of the students had the technical capacity to access most library services as most of their mobile phones had internet capability. This evidence implies that, besides the web-based services offered in many libraries such as mobile databases, catalogues and circulation, students could also access basic services of feature phones, such as SMS notifications, renewals and information services (Jetty and Anbu 2013).

Internet capability is one of the important features of a smartphone, others being Wi-Fi capabilities, a QWERTY keyboard (either physical or virtual) and touch screen (Song and Lee 2012, Yu 2012). Much as the study did not specifically find out whether the mobile phones that respondents owned were smartphones or feature phones, it could point to a high prevalence of smartphones among the students, reflecting findings of a study by Palumbo (2014) who had observed that smartphones were becoming pervasive on the African continent.

\subsection{Access to library resources using mobile phones}

The term 'library resources' is used to refer to electronic information resources offered in many academic libraries. These include e-books, e-journals, the library website and the OPAC. In this study, students were asked to indicate if they have ever accessed these resources using their mobile phone. Their responses are presented in Figure 4, and they show that the majority of the students $(165 ; 52.9 \%)$ had used their mobile phone to access e-books while $149(47.8 \%)$ had used their mobile phone to access e-journals. A considerable number of students (110; 35.3\%) also reported using their mobile phones to access the library website while only a few $(37 ; 11.9 \%)$ used their mobile phone to access the OPAC. However, some of the respondents did not seem to understand what the term OPAC meant, and perhaps its actual use could be higher than what was reported in the study.

Figure 4 Access to information resources using mobile phone by students $(\mathrm{N}=312)$

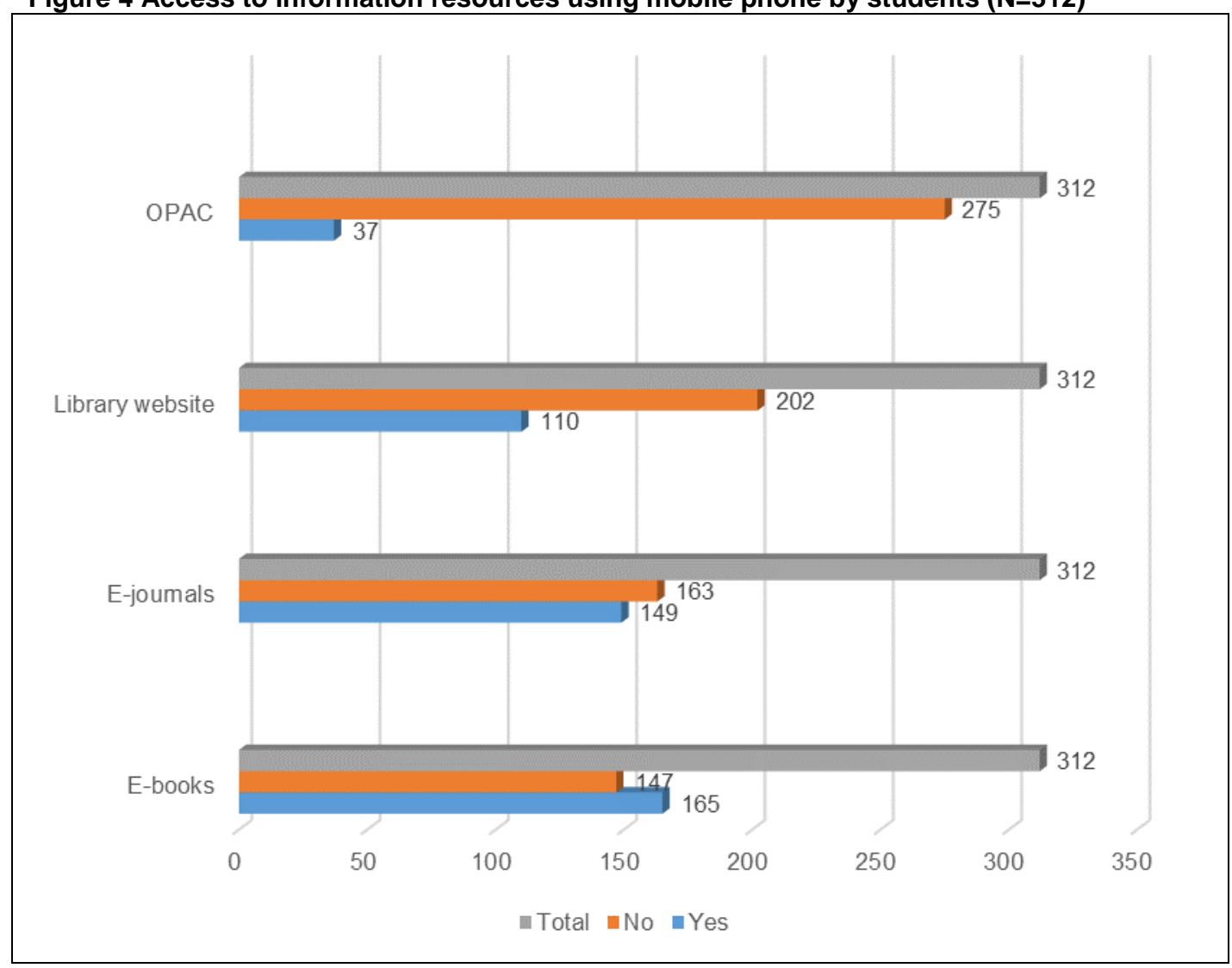

Studies conducted by Lo et al. (2016) in Hong Kong and Vassilakaki, Moniarou-Papaconstantinou and Garoufallou (2016) in Greece have also shown that students used their mobile phones for library-related purposes. However, like what was established in the current study, the two studies revealed that usage of mobile phones for reading journal articles, ebooks, as well as searching the library catalogue, was minimal. The study by Vassilakaki, Moniarou-Papaconstantinou and Garoufallou (2016) indicated that most students rejected the use of mobile phones to access e-books, e-journals, the library website and the OPAC, preferring instead to access these resources using laptop computers. 


\subsection{Use of mobile phone to access library reference services}

Students were further asked to indicate if they had ever used their mobile phone to call, email or text the library to seek help or access any reference service. An analysis of their findings (as presented in Table 1) shows that, cumulatively, only sixty $(20 \%)$ students had ever used their mobile phones to call, email or text the library to seek help or access reference services 'rarely' or 'frequently' while the rest (240; $80 \%)$ were either not sure or had never done so. Further analysis of the findings revealed that students at LUANAR (fourteen; 34.1\%) used their mobile phones to access reference services more than their colleagues in the other institutions, followed by their colleagues at KCN (four; $20 \%$ ), the Polytechnic (twenty-three; 19.7\%) and MZUNI (fifteen; 19.5\%). Students from COM used their mobile phones the least (four; $8.9 \%$ ) to get in touch with the library for help or to access any reference service.

Table 1 Students' use of mobile phone to call, email or text the library to seek help or access reference services ( $\mathrm{N}=300$ )

\begin{tabular}{|c|c|c|c|c|c|c|}
\hline \multirow{2}{*}{$\begin{array}{l}\text { Name of } \\
\text { institution }\end{array}$} & \multicolumn{5}{|c|}{$\begin{array}{l}\text { Have you ever used your mobile phone to call, email or text the library to seek help or access any } \\
\text { reference service? }\end{array}$} & \multirow[t]{2}{*}{ Total } \\
\hline & Yes, frequently & Yes, but rarely & Not sure & Hardly use & Never used & \\
\hline \multirow{2}{*}{ MZUNI } & 5 & 10 & 5 & 17 & 40 & 77 \\
\hline & $6.5 \%$ & $13 \%$ & $6.5 \%$ & $22.1 \%$ & $51.9 \%$ & $100 \%$ \\
\hline \multirow{2}{*}{$\mathrm{KCN}$} & 0 & 4 & 0 & 9 & 7 & 20 \\
\hline & $0 \%$ & $20 \%$ & $0 \%$ & $45 \%$ & $35 \%$ & $100 \%$ \\
\hline \multirow{2}{*}{ Polytechnic } & 9 & 14 & 8 & 38 & 48 & 117 \\
\hline & $7.7 \%$ & $12 \%$ & $6.8 \%$ & $32.5 \%$ & $41 \%$ & $100 \%$ \\
\hline \multirow{2}{*}{$\mathrm{COM}$} & 1 & 3 & 2 & 15 & 24 & 45 \\
\hline & $2.2 \%$ & $6.7 \%$ & $4.4 \%$ & $33.3 \%$ & $53.3 \%$ & $100 \%$ \\
\hline \multirow{2}{*}{ LUANAR } & 6 & 8 & 1 & 11 & 15 & 41 \\
\hline & $14.6 \%$ & $19.5 \%$ & $2.4 \%$ & $26.8 \%$ & $36.6 \%$ & $100 \%$ \\
\hline \multirow{2}{*}{ Total } & 21 & 39 & 16 & 90 & 134 & 300 \\
\hline & $7 \%$ & $13 \%$ & $5.3 \%$ & $30 \%$ & $44.7 \%$ & $100 \%$ \\
\hline
\end{tabular}

Figure 5 Mobile phone applications students used to access reference services from the library $(\mathrm{N}=66)$

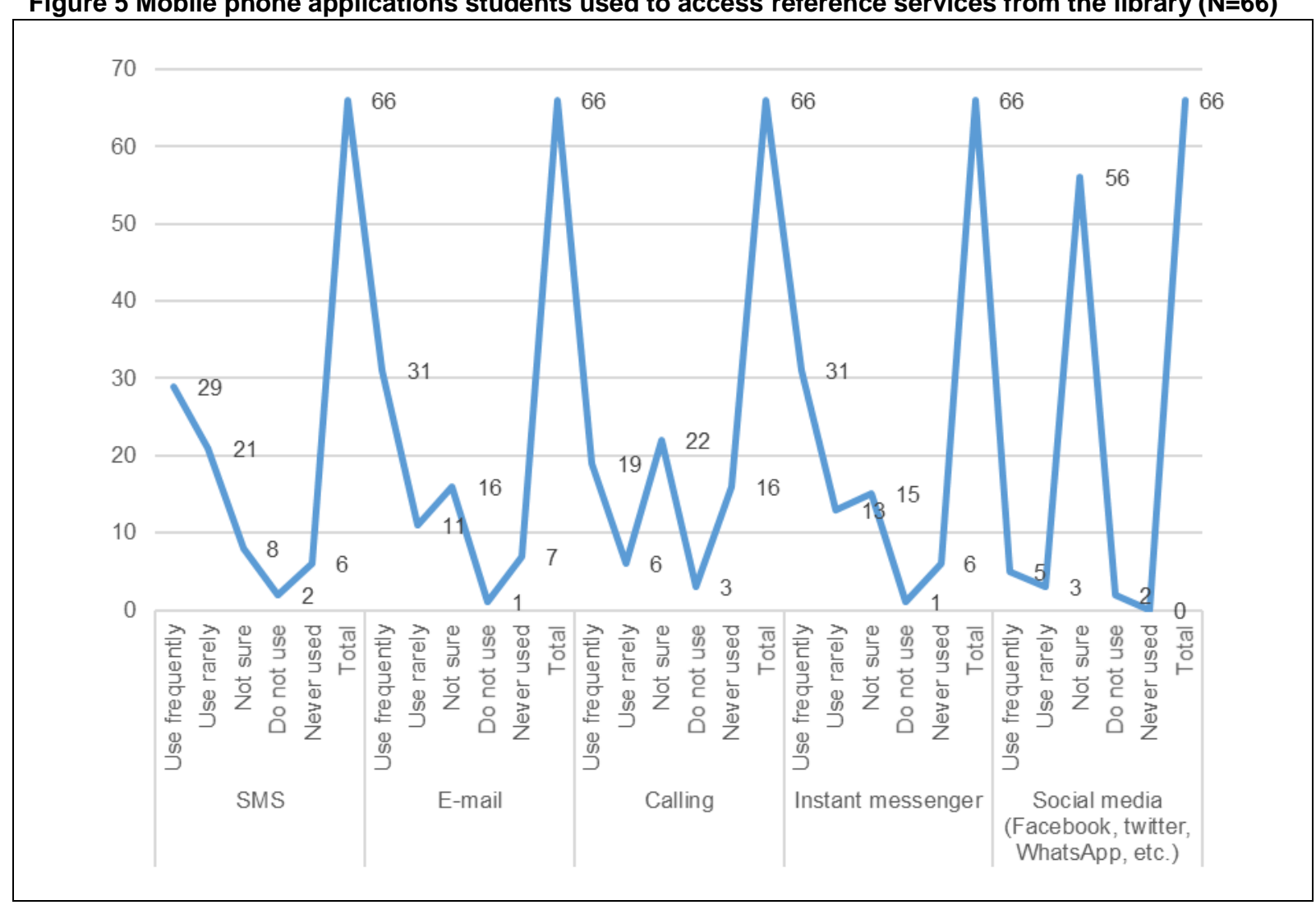


Overall, usage of mobile phones by students to access reference services from the library was low, though use was comparatively higher at LUANAR and KCN. Related studies on the use of mobile phones to access library services have shown similar results. For instance, a study conducted by Hossain and Ahmed (2016) on the use of smartphones for academic purposes by students at Dhaka University in Bangladesh revealed that only forty-eight (23.2\%) students used smartphones for library reference services. Similarly, an ECAR (2014) study of undergraduate students' use of technology discovered that over $50 \%$ of students used their mobile devices (smartphones and tablets) to access library resources (Dahlstrom and Bichsel 2014). Nevertheless, this figure was one of the lowest reported uses of mobile phones in that study.

Students who indicated that they have used their mobile phone to contact the library to access reference services were asked to indicate the mobile phone applications they used. An analysis of their findings (as presented in Figure 5) revealed that students frequently used instant messenger (31;47\%), email (31;47\%), SMS (29; 43.9\%) and call function $(19 ; 28.8 \%)$ to contact the library. However, students did not frequently use social media tools such as Facebook, Twitter or WhatsApp (five; $7.8 \%$ ) to contact the library to access reference services.

\subsection{Factors impacting usage of mobile phones by students to access library resources and services}

The respondents were asked to indicate why they used mobile phones over other available means (that is, laptop computers) to access library resources and services. Findings for this query are presented in Table 2 and they show that the majority of students either strongly agreed $(143 ; 63 \%)$ or agreed $(57 ; 25.1 \%)$ that they used mobile phone to access information resources over other available means such as laptops because mobile internet was available from anywhere, at any time, hence was more convenient to use. The rest of the students either expressed no opinion $(14 ; 6.2 \%)$, disagreed $(11 ; 4.8 \%)$ or strongly disagreed $(2 ; 0.9 \%)$ with this statement. Some of the reasons that led to students using mobile phones over other available resources were that it was easier to access services using mobile phones; because of a shortage of work stations in the computer labs; because mobile internet was more reliable; and because mobile internet was cheaper to use. On the other hand, most of the students disagreed with the statement that they used a mobile phone over other available means because they were influenced by a friend or because of frequent power outages in computer labs. Students who did not use mobile phones to access library resources and services were asked to indicate factors that prevented them from doing so. Findings to this query (as presented in Figure 6) show that the small screen size of mobile phones that made reading difficult, the high cost of mobile internet, and library websites that were not mobile friendly were the main reasons.

Table 2 Why students used mobile phones over other available means to access library resources and services ( $\mathrm{N}=227$ )

\begin{tabular}{|c|c|c|c|c|c|c|}
\hline $\begin{array}{l}\text { Reason for using mobile phone over } \\
\text { other means, that is, laptops }\end{array}$ & $\begin{array}{l}\text { Strongly } \\
\text { agree }\end{array}$ & Agree & No opinion & Disagree & $\begin{array}{l}\text { Strongly } \\
\text { disagree }\end{array}$ & Total \\
\hline \multirow{2}{*}{$\begin{array}{l}\text { Mobile internet is available from } \\
\text { anywhere, anytime hence more } \\
\text { convenient to use }\end{array}$} & 143 & 57 & 14 & 11 & 2 & 227 \\
\hline & $63 \%$ & $25.1 \%$ & $6.2 \%$ & $4.8 \%$ & $0.9 \%$ & $100 \%$ \\
\hline \multirow{2}{*}{ Mobile internet is more reliable } & 66 & 82 & 47 & 29 & 3 & 227 \\
\hline & $29.1 \%$ & $36.1 \%$ & $20.7 \%$ & $12.8 \%$ & $1.3 \%$ & $100 \%$ \\
\hline \multirow{2}{*}{ PC shortage in computer labs } & 75 & 63 & 47 & 32 & 10 & 227 \\
\hline & $33 \%$ & $27.8 \%$ & $20.7 \%$ & $14.1 \%$ & $4.4 \%$ & $100 \%$ \\
\hline \multirow{2}{*}{$\begin{array}{l}\text { Frequent power outages in computer } \\
\text { labs }\end{array}$} & 35 & 44 & 53 & 68 & 27 & 227 \\
\hline & $15.4 \%$ & $19.4 \%$ & $23.3 \%$ & $30 \%$ & $11.9 \%$ & $100 \%$ \\
\hline \multirow{2}{*}{ Mobile internet is cheaper to use } & 96 & 48 & 31 & 36 & 16 & 227 \\
\hline & $42.3 \%$ & $21.1 \%$ & $13.7 \%$ & $15.9 \%$ & $7 \%$ & $100 \%$ \\
\hline \multirow{2}{*}{ Book shortage in the library } & 82 & 71 & 37 & 27 & 10 & 227 \\
\hline & $36.1 \%$ & $31.3 \%$ & $16.3 \%$ & $11.9 \%$ & $4.4 \%$ & $100 \%$ \\
\hline \multirow{2}{*}{$\begin{array}{l}\text { It is easier to access services using } \\
\text { mobile phone }\end{array}$} & 96 & 89 & 27 & 12 & 3 & 227 \\
\hline & $42.3 \%$ & $39.2 \%$ & $11.9 \%$ & $5.3 \%$ & $1.3 \%$ & $100 \%$ \\
\hline \multirow{2}{*}{ Influenced (copied) from a friend } & 17 & 24 & 59 & 74 & 53 & 227 \\
\hline & $7.5 \%$ & $10.6 \%$ & $26 \%$ & $32.6 \%$ & $23.3 \%$ & $100 \%$ \\
\hline
\end{tabular}

Average Cronbach's Alpha value of the items in Table 2 was 0.665 
The UTAUT model states that behavioural intention to use technology is driven by, among others, performance expectancy and effort expectancy. Performance expectancy is defined as the degree to which an individual believes that using the system will help him or her achieve in a job while effort expectancy is defined as the degree of ease associated with the use of the system (Venkatesh et al. 2003). Findings of this study show that students chose to access e-books and e-journals using mobile phones over other resources such as laptops because they expected higher performance (mobile internet is more reliable) with minimal effort (mobile internet is available from anywhere, at any time, hence, it is more convenient to use; it is easier to access services using mobile phone). Findings of this study further indicated that some of the students did not access e-books and e-journals using mobile phone as a result of the influence of a friend. This discovery shows that the construct of social influence did not have an impact on technology use, which is similar to what Venkatesh et al. (2003) found in validating the UTAUT model when they concluded that this construct is only significant in mandatory contexts and becomes non-significant in voluntary settings.

Figure 6 Reasons for not using mobile phones to access information resources by students $(\mathrm{N}=138)$

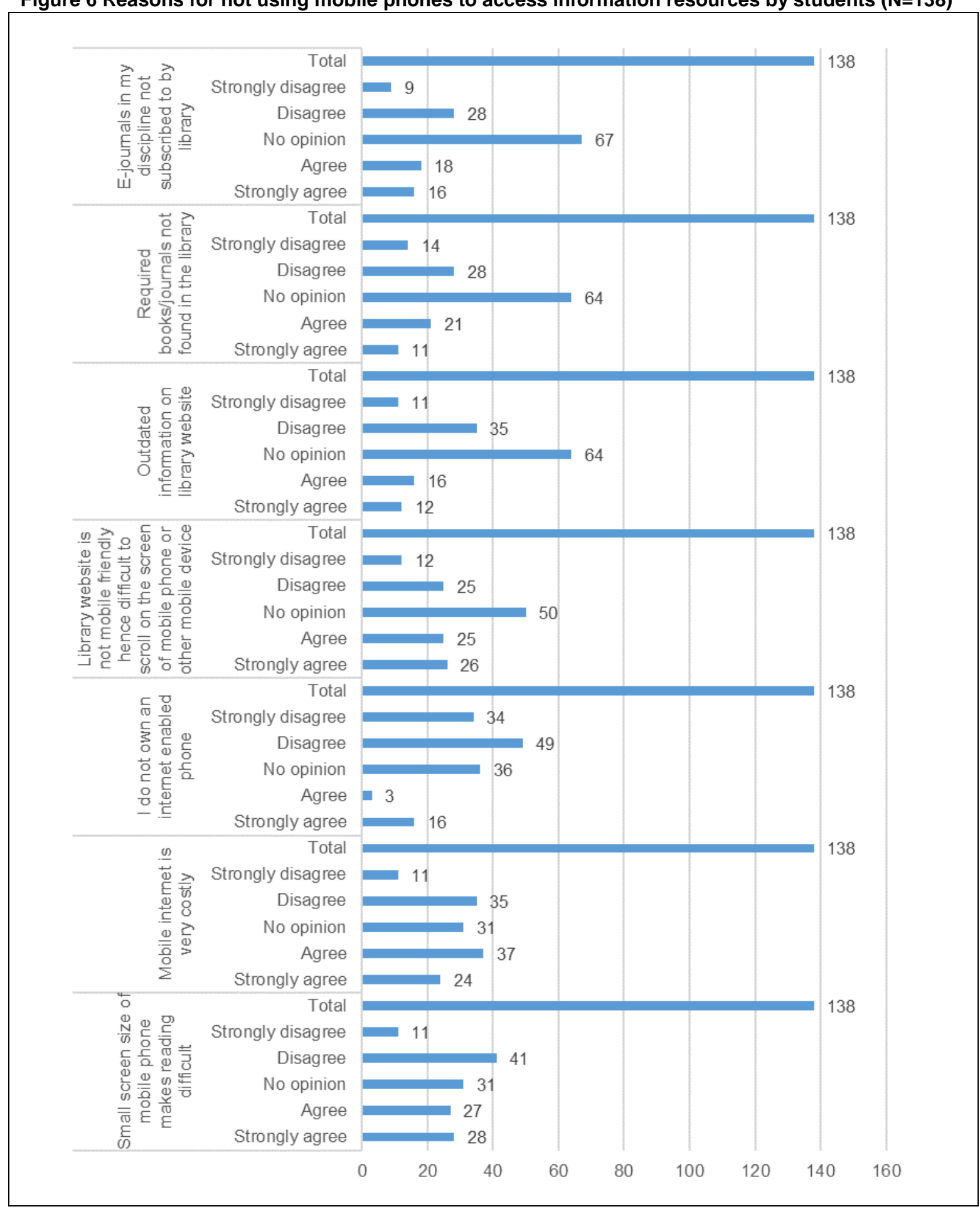




\section{Conclusions and future research}

Despite the high prevalence of mobile phones (315; 99.7\%) and pervasiveness of internet-capable mobile phones (299; $94.9 \%$ ) among students, this study concluded that usage of these devices for accessing library resources and services was generally low, falling below the $50 \%$ mark in both instances. Notwithstanding this finding, usage of mobile phones to access e-books, e-journals and the library website was high, with close to half of all students reporting to have accessed them in this way. However, usage of mobile phones to access reference services from the library was low with only sixty $(20 \%)$ students reporting usage. The study did not investigate factors responsible for the disparities in usage observed. However, previous studies have shown that patrons prefer face-to-face reference compared to help via mobile phones, particularly SMS, because this type of reference service lacks sophistication and is dogged by delays in response times (Murray 2010, Pearce, Collard \& Whatley 2010). Moreover, lack of knowledge of the existence of these resources and services could be a factor.

Like what was found in previous studies by Vassilakaki, Moniarou-Papaconstantinou and Garoufallou (2016) and Lo et al. (2016), technological characteristics of mobile phones (small screen size of mobile phone that made reading difficult and library websites that were not mobile friendly) and the high cost of access to mobile phone services have been highlighted as factors that could negatively impact usage of mobile phones for accessing library services. A study conducted by Research ICT Solutions (2015), while acknowledging that call costs had reduced over the years, still concluded that call tariffs were higher in Malawi when compared to neighbouring countries, showing that the respondents' observations on cost could be valid. Additionally, concerns related to the small screen size of mobile phone are equally valid as the market is awash with such type of mobile phone models. However, such issues could be resolved over time as mobile phones become bigger. Likewise, the pervasiveness of smartphones and increased access of library websites through the mobile web would compel institutions to design mobile-friendly websites. Besides, the study identified other factors that positively impacted use of mobile phones to access library resources and services. The ease of accessing services using a mobile phone and the reliability of mobile internet were identified as factors. Lack of computers in the computer laboratories and frequent power blackouts that impacted usage of computers in the laboratories were also indicated as factors that positively impacted respondents' use of mobile phones to access resources such as e-books and e-journals.

The overall conclusion of this study is that technological aspects associated with the mobile phone and cost are the main factors impacting usage of mobile phones to access library resources and services. However, the study failed to reach a definite conclusion on the factors responsible for the disparities in usage of mobile phone for library purposes and social functions. Nevertheless, it is assumed that lack of knowledge of the existence of the library services and resources and how students value them, coupled with the possibility of accessing these resources and services through alternative means, such as a computer, could explain this phenomenon. Since the impact of these factors on usage of mobile phones has not been explored, future research should focus on this area.

\section{References}

Akeriwa, M., Penzhorn, C. and Holmner, M. 2015. Using mobile technologies for social media based library services at the University of Development Studies Library, Ghana. [Online]. http://repository.up.ac.za/bitstream/handle/2263/45342/Akeriwa_Using_2015.pdf?sequence=1\&isAllowed=y (25 October 2015).

Ballard, T.L. and Blaine, A. 2013. A library in the palm of your hand. New Library World, 114(5/6): 251-258.

Becker, A., Bonadie-Joseph, D. and Jonathan, I.C. 2013. Developing and completing a library mobile technology survey to create a user-centered mobile presence. Library Hi Tech, 31(4): 688-699.

Bomhold, C. 2014. Mobile services at academic libraries: meeting the users' needs? Library Hi Tech, 32(2): 336-345.

Brooks, D.C. 2015.. ECAR Study of Faculty and Information Technology. Research report. Louisville, CO: ECAR. [Online]. http://www.educause.edu/ecar (25 May 2016).

Brooks, D.C. 2016. ECAR Study of Faculty and Information Technology, 2016. Research report. Louisville, CO: ECAR, October 2016. Available at: http://www.educause.edu/ecar. (Accessed 15 November, 2017).

Carlsson, C., Carlsson, J., Hyvönen, K., Puhakainen, J. and Walden, P. 2006. Adoption of mobile devices/services searching for answers with the UTAUT. Proceedings of the 39th Hawaii International Conference on System Sciences. 4-7 January 2006. Kauia, Hawaii: IEEE [Online]. http://ieeexplore.ieee.org/xpls/abs_all.jsp?arnumber=1579556\&tag=1 (09 August 2015)

Chang, C. 2013. Library mobile applications in university libraries. Library Hi Tech, 31(3): 478-492.

Chen, K. and Chang, M. 2013. User acceptance of 'near field communication' mobile phone service: an investigation based on the 'unified theory of acceptance and use of technology' model. The Service Industries Journal, 33(6): 609623.

Dahlstrom, E. and Bichsel, J. 2014. ECAR study of undergraduate students and information technology (Research report). Louisville, CO: ECAR. [Online]. https://net.educause.edu/ir/library/pdf/ss14/ERS1406.pdf (25 October 2015). 
Dahlstrom, E., Brooks, D.C., Grajek, S. and Reeves, J. 2015. ECAR study of students and information technology (Research report). Louisville, CO: ECAR.

Dahlstrom, E., Walker, J.D. and Dziuban, C. 2013. ECAR study of undergraduate students and information technology (Research report). Louisville, CO: ECAR. [Online]. https://net.educause.edu/ir/library/pdf/ERS1302/ERS1302.pdf (25 October 2015).

De Wee, J.A. 2013. An investigation into how mobile technologies can advance service delivery for library users at the University of Pretoria Library Services. Master's thesis. University of Pretoria.

Dewah, P. and Mutula, S. 2013. Mobile phones access and use among students at the National University of Technology (NUST) Bulawayo, Zimbabwe: implications for academic integrity. Innovation, 46: 150-165.

Fasae, K.J. and Adegbilero-Iwari, I. 2015. Mobile devices for academic practices by students of college of sciences in selected Nigerian private universities. The Electronic Library, 33(4): 749-759.

Haverila, M. 2013. Cell phone usage and broad feature preferences: a study among Finnish undergraduate students. Telematics and Informatics, 30(2): 177-188.

Hossain, M.E. and Ahmed, S.M.Z. 2016. Academic use of smartphones by university students: a developing country perspective. The Electronic Library, 34(4): 651-665.

Jetty, S. and Anbu, J.P.K. 2013. SMS-based content alert system: a case with Bundelkhand University Library, Jhansi. New Library World, 114(1/2): 20-31.

Keong, M.L., Ramayah, T., Kurnia, S. and Chiun, L.M. 2012. Explaining intention to use an enterprise resource planning (ERP) system: an extension of the UTAUT model. Business Strategy Series, 13(4): 173-180.

Kijsanayotin, B., Pannarunothai, S. and Speedie, S.M. 2009. Factors influencing health information technology adoption in Thailand's community health centers: applying the UTAUT model. International Journal of Medical Informatics, 78: 404-416.

Kubat, G. 2017. The mobile future of university libraries and an analysis of the Turkish Case. Information and Learning Science, 118(3/4): 120-140.

Kumar, A. 2014. Students opinion about the success of mobile technology in libraries. New Library World, 115(9/10): $471-481$.

Lo, P., Cho, A., Leung, M., Chiu, D.K.W., Ko, E.H.T. and Ho, K.K.W. 2016. Use of smartphones by art and design students for accessing library services and learning. Library Hi Tech, 34(2): 224-238.

Luo, L. 2014. Text a librarian: a look from the user perspective. Reference Services Review, 42(1): 34-35.

Malik, A. and Mahmood, K. 2013. Infrastructure needed for digital reference service (DRS) in university libraries: an exploratory survey in the Punjab, Pakistan. Library Review, 62(6/7): 420-428.

Martin, H.S. and Herrero, A. 2012. Influence of the users' psychological factors on the online purchase intention in rural tourism: integrating innovativeness of the UTAUT framework. Tourism Management, 33: 341-350.

Murray, L. 2010. Libraries "like to move it, move it”. Reference Services Review, 38(2): 233-249.

Nowlan, G. 2013. Going mobile: creating a mobile presence for your library. New Library World, 114(3/4): 142-150.

Palumbo, L.B. 2014. Mobile phones in Africa: opportunities and challenges for academic librarians. New Library World, 115(3/4): 179-192.

Pearce, A., Collard, S. and Whatley, K. 2010. SMS reference: myths, markers, and modalities. Reference Services Review, 38(2): 250-263.

Research ICT Solutions. 2015. Malawi's phone tariffs among highest in Africa. Daily Times, 16 January.

Song, Y. and Lee, J. 2012. Mobile device ownership among international business students: a road to the ubiquitous library. Reference Services Review, 40(4): 574-588.

Straub, D. W. and Burton-Jones, A. 2007. Veni, vedi, vici: breaking the TAM logjam. Journal of the Association for Information Systems, 8(4): 223-229.

Vassilakaki, E., Moniarou-Papaconstantinou, V. and Garoufallou, E. 2016. Identifying the uses of mobile technology among Library and Information Science undergraduate students. Program, 50(4): 417-430.

Venkatesh, V., Morris, M. G., Davis, G. B. and Davis, F. D. 2003. User acceptance of information technology: toward a unified view. MIS Quarterly, 27(3): 425-478.

Wang, H. and Wang, S. 2010. User acceptance of mobile internet-based on the Unified Theory of Acceptance and Use of technology: investigating the determinants and gender differences. Social Behavior and Personality, 38(3): 415-426.

Williams, M.D., Rana, N.P. and Dwivedi, Y.K. 2012. A bibliometric analysis of articles citing the Unified Theory of Acceptance and Use of Technology. In Information systems theory: explaining and predicting our digital society.Dwivedi, Wade \& Schneberger, Eds. Springer: London. 37-62.

Yu, F. 2012. Mobile/smart phone use in higher education. Paper presented at the Southwest Decision Sciences Institute Conference. 29 FEbrurary - 3 March 2012. ). 4-8 June 2012. Houston,Texas. [Online]. http://swdsi.org/swdsi2012/proceedings_2012/papers/Papers/PA144.pdf (25 October 2015).

Zhang, M., Shen, X., Zhu, M. and Yang, J. 2016. Which platform should I choose? Factors influencing consumers' channel transfer intention from web-based to mobile library service. Library Hi Tech, 34(1): 2-20. 